\title{
The role of Experimental Stress Analysis at graduation and post graduation courses - A Brazilian case.
}

\author{
R.J.P.C. Miranda ${ }^{1, a}$, P. Domingues ${ }^{2, b}$, L.M. Zamboni ${ }^{3, c}$, J. C. Salamani ${ }^{4, d}$ \\ ${ }^{1}$ Head Professor on Mechanics of Materials, Solid Mechanics, Finite Element Method and \\ Experimental Stress Analysis in Centro Universitario da FEI(FEI), São Bernardo do Campo, and \\ CEUN-IMT, São Paulo, Brazil.
}

${ }^{2}$ Mechanical of Materials Student and Monitor in Centro Universitario do Instituto Mauá de Tecnologia(IMT), São Caetano do Sul, São Paulo, Brazil.

${ }^{3}$ M.Sc. in Mechanical Engineering in São Paulo University(USP) B.Sc. in Mechanical Engineering(FEl).

${ }^{4} \mathrm{M}$ Sc. in Naval Engineering (USP) - Professor on Automotive Engineering in $\mathrm{FEl}$ in undergraduate and graduate courses.

arenatocmiranda@yahoo.com.br; bedro.modomingues@hotmail.com; Imzamboni@gmail.com; djcsala@uol.com.br;

Reviewer: D.R. Maiuri- M.Sc. in Energy (USP) ; Specialization on Fluid and Thermal Studies for Industry(University of Bristol, U.K.); B Sc. in Mechanical Engineering (University of Illinois, USA); Head Professor on Applied Thermodynamics and Coordinator of specialization courses in FEl.

Keywords: Experimental Stress Analysis, Solid Mechanical, Mechanical of Materials, Mechanical Engineer, Structures, Strain-gauges, Residual Stress Measurement.

Abstract. This paper presents an alternative to the theoretical classic teaching methods generally used in Strength of Materials or Solids Mechanics. It introduces a dynamic and interactive process, with emphasis in the use of ESA-Experimental Stress Analysis, especially strain gauges and photoelasticity. In addition to the didactic and practical experiments, the students used all their energy and creativity to develop the interesting results presented here, such as, experimental device for measuring displacement, Buckling, Spaghetti and Popsicle sticks Bridges, Stress analysis in a cylinder block and Mini Baja project.

\section{Introduction}

This work is a continuation and an updating on the paper mentioned in Reference [1], presented on 2003 in the Annual Conference and Exposition on Experimental and Applied Mechanics, sponsored by Society for Experimental Mechanics in Charlotte, North Caroline, USA.

Most Brazilian Mechanical Engineering Schools still use an instructor-based method for teaching Strength of Materials. This leads to small participation and interaction, and, consequently, to high failure indexes.

It must be recognized the importance of encouraging practical activities, especially in laboratory, as a mean to help future engineers to absorb new theoretical concepts, to increase their sensibility, to get acquainted with measuring equipment, to develop a critical vision, to develop team work, to stimulate their creativity, to acquire abilities for preparing reports, to compare experimental results with those obtained from classical, analytical and numerical methods, and, finally, to arrive to the correct conclusions for the solutions of modern engineering problems $[1,20]$. 
Looking from this viewpoint, it is necessary that engineering schools introduce experiments, research and services in many knowledge areas.

We understand that all subjects should be related to a lab center and maintain systematic practical activities throughout the course.

In the case of FEI - Centro Universitário da FEI, the Solid Mechanical Laboratory, also called Experimental Stress Analysis Laboratory, was inaugurated in 1984, after some years of research, performed by professors and students in Brazil and abroad, specially through an agreement between FEI and ENSAM - Ecóle Nationale Superieure d'Arts et Metiers, Paris, France. This Laboratory is related to the subject Solid Mechanics, with two obligatory hours a week, in which all junior mechanical engineering students have a global vision of experimental stress analysis techniques, mainly electric extensiometry and Photo-elasticity.

The Solid Mechanical Lab is in constant updating, and, together with the Materials Lab and other labs, constitute the CLM - Mechanical Laboratories Center, which provides conditions for scientific initiation projects, undergraduate projects, researches and services for industry.

Instructors and students from the undergraduate and graduate courses present their statements and didactic equipment to illustrate the importance of experimental stress analysis in the mechanical engineering teaching $[2,3,5,7]$. analysis:

Some works presented in this paper aim to prove the importance of experimental stress

Experimental devices for measuring displacement and rotation in flexion

Device for analysis of buckling in bars

Spaghetti and Popsicle sticks Bridge

Experimental stress analysis in a cylinder block

Mini Baja project

\section{The importance of teaching material}

As mentioned in previous works, the success of a good course depends on the discussion and preparation of an appropriate teaching plan for instructors, students and staff. Everybody must be prepared for the use of laboratories and acquainted with the corresponding literature.

In the case of Experimental Stress Analysis, which is a part of our course in Solid Mechanics, we use as a basic reference the book Mechanics of Materials [6], which is now in its fifth edition.

Our library maintains about 300 copies of this reference. It has excellent supplementary learning materials for students and teachers, specially the interactive tutorial and a great site "On line learning center". It also presents theoretical applications on 50 single and multiple gauges.

Complementary bibliography, such as Hibbeler's [16] and other works, are also used.

Considering only Experimental Stress Analysis, we used Dally and Riley [18], and the Encyclopedie D'Analyse des Constraints [19].

We extensively use as references catalogs and web sites of Brazilian and international manufacturers, as MM-Vishay [22], Kyowa [24], HBM [21] and Excel [23], as well as magazines and newspapers, such as BSSM Strain [17] and EMS-Experimental Mechanics [25].

Our work is supported by the intensive use of computational tools, such as Moodle and others e-learning tools.

\section{Experimental devices for measuring displacement and rotation in flexion}

When we apply a given bending moment on a beam, it undergoes a deformation, which causes displacement and rotation. To make that clear, during the teaching of displacement inflexion, it's important that the student sees what is happening. This will help him to understand the process.

To help the student to visualize the effects, can be developed devices to simulate the action of efforts in a bar, making visible the deformations and allowing their measurement. 
Students created a device that allows the visualization of displacements on the bending of a simply supported beam, which receives the action of two forces acting on specific points. Thus, the student can visualize the displacements of the bar and also confirm the accuracy of the calculations. The layout of this beam is shown in Figures 1 and 2.

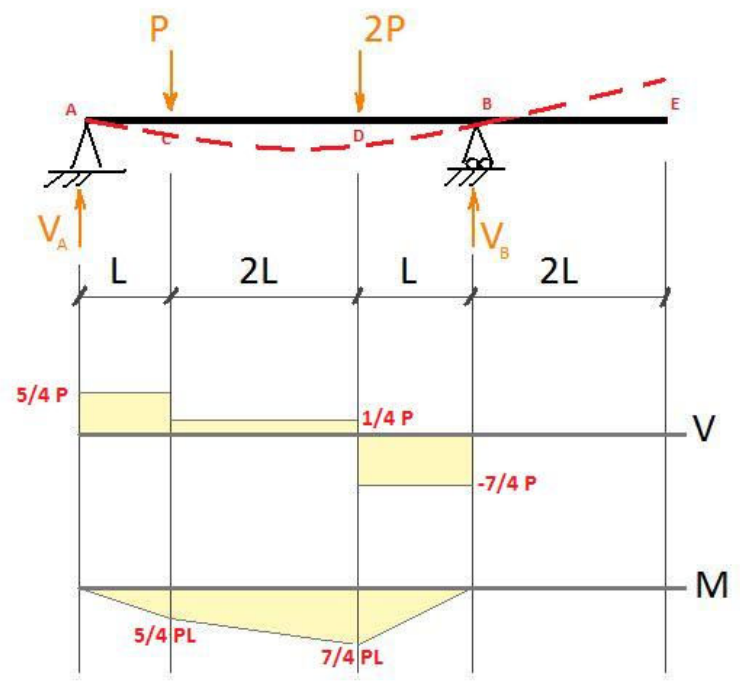

Layout of the beam and the forces applied (Figure 1)

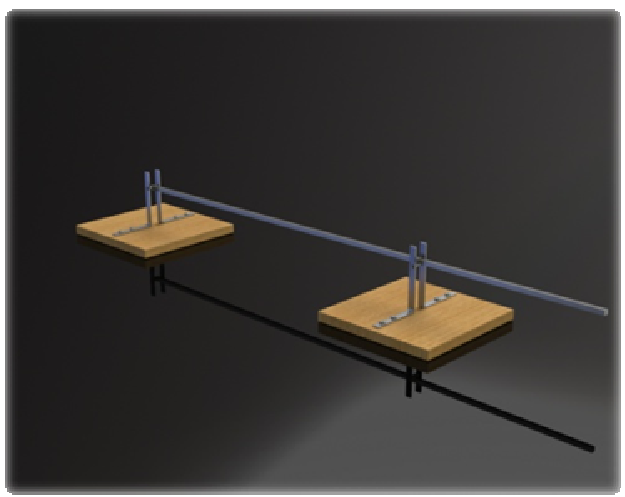

Device build by a group of students (Figure 2)

This work allowed the students, using the theory of integration of elastic line, with or without the use of singular functions, to calculate the displacement and rotation in sections A, B, C, $\mathrm{D}$ and $\mathrm{E}$. The theoretical results were then compared with the experimental results, obtained through the device built by the group. We observed that the deviation of results was acceptable $[4,6,16]$.

\section{Device for analysis of buckling in bars.}

This interesting device, inspired by references [10,11,12,13], allows the student to determine experimentally the buckling load for the 4 major cases of linking, which are illustrated on Figures 3 to 7 :

- Pin-connected at both ends (Fig. 3)

- One end fixed and the other pin-connected (Fig. 4)
- Two fixed ends (Fig. 5)

- One end fixed and the other free (Fig. 6)

The equipment allows us to view the deformed (elastic line) on each case, depending on the conditions of linking.

The experimental determination of the load can be done by calibrated weights or other process. When the results obtained experimentally are compared with those obtained theoretically, it is possible too demonstrate the accuracy of the theory.

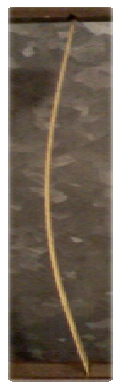

(Figure 3)

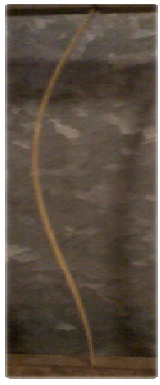

(Figure 4)

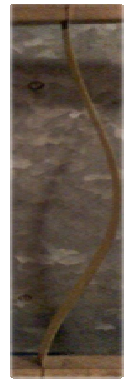

(Figure 5)

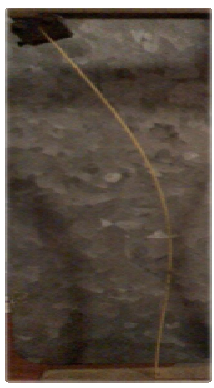

(Figure 6)

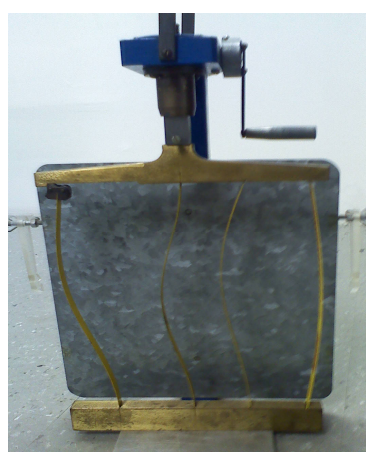

Buckling Device (Figure 7)

\section{Traditional Spaghetti and Popsicle sticks Bridges}

The Spaghetti Bridge Contest is a traditional competition in many Brazilian and international universities. It aims to develop in the students the use of their creativity, theoretical 
and practical knowledge to build a bridge that can withstand a load much greater than its own weight.

Some other universities have designed, built and developed bridges using popsicle sticks, instead of the traditional spaghetti.

The main elements that are developed are the lattice, since most bars only withstand normal forces, and buckling, because some bars suffer compression and tend to suffer instability of balance.

The students develop a report, where they analyze the forces of tension and compression that act on each bar and the maximum strength supported, taking into account the maximum allowable stresses. When the bar suffers buckling we should analyze the parameters involved, such as moment of inertia, area, radius of gyration, the equivalent length of buckling, effective slenderness ratio of the column, slenderness limit of material and the elastic(Euler) or plastic (other theories) buckling.

Consequently, the students have the opportunity to compare theoretical concepts to the real thing, and to see the problems and difficulties that occur during the construction process, as well as their influence in the final result.

As an example, it can be verified how a problem of alignment or symmetry, which make the forces to be differently distributed than calculated, can change the maximum load to be resisted by the bridge.

Through this competition the students develop a real ability to reason, leaving aside the mathematical estimative and learning to analyze and develop a structure in a different way. This helps the absorption of the involved concepts.

It must be added that the student's participation in the contest develops skills of team working, leadership and critical vision [4,20].

To illustrate this event we annex Figure 8 and 9.

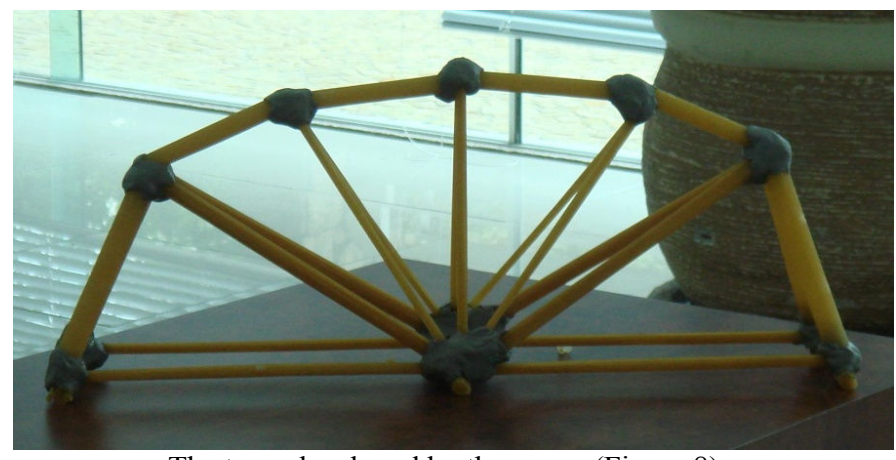

The truss developed by the group (Figure 8)

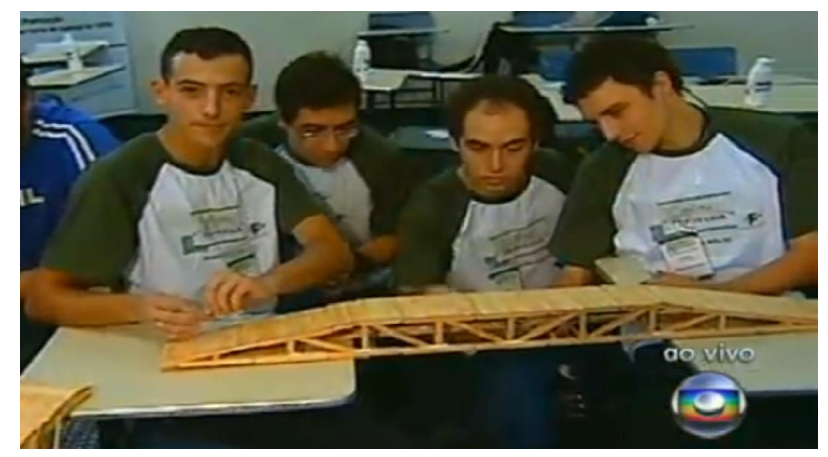

Popsicle sticks Bridge of a student's group (Figure 9)

\section{Experimental stress analysis applied to internal combustion engine design}

Under the new scenery of green house effects, modern internal combustion engine design must consider the effects of exhaust gas and emissions. To attain new requirements and legislation, low emission levels are very important.

The design of rings, piston, and cylinders are fundamental in this new development concept. Manufacturers are applying efforts to develop geometries to improve performance in reference to emissions. However, the cylinder liner plays an outstanding role. Circularity, linearity and the cylinder liner shape are responsible for the working stability of the piston and rings, also affecting their durability.

Oil consumption and combustion gas exhaustion are fundamental for emission control. The geometrical deformations are, among other reasons, due to residual stress. Such stresses come from manufacturing processes but also as a residual effect, created at foundry or during casting processes, and must be properly evaluated.

$\mathrm{X}$ - Ray surface analysis is one of the methods for such evaluation. However, many times it is not available and is always very expensive. Strain gauge evaluation of a cylinder liner is easy and simple. Just three strain gauges installed on the surface of the liner (rosette shape) will make possible to take a cross section cut of the liner. It is then possible to obtain the strain level before 
and after the cut and have a data bank of strain values with and without stress relieve, at several situations. It is then possible to organize a very simple and accurate procedure for stress control in the cylinder liner.

\section{Mini Baja - FEI three times world champion and Formula FEI}

In Reference [8] it is shown that the Mini Baja vehicles developed in FEI are instrumented with several strain gauges and systems of data acquisition, which lead to improving projects and reducing their weights. The result was that FEI's truggy was considered the world's best in Montreal, and Formula FEI was considered among the world's Top 10 in 2009, in Detroit. (See Figures 10 e 11)

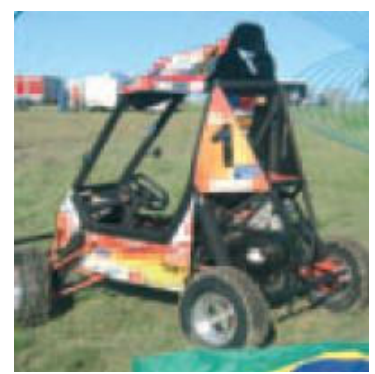

Mini Baja (Figure 10)

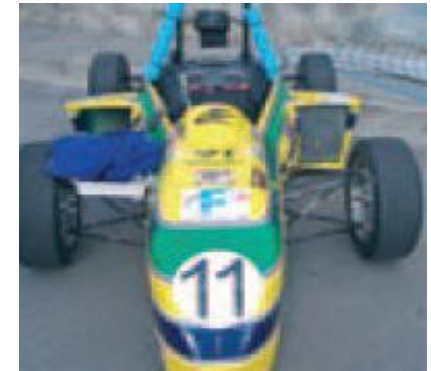

Fórmula FEI (Figure 11)

Vehicles developed by IMT - Instituto Mauá de Tecnologia were also analyzed experimentally and obtained good results in national and international competitions.

\section{Conclusion}

The pedagogic technique, that use contest or competitions of projects, prototypes or similar, to stimulate the creativity and responsibility on the students, in activities like Mini Baja, Formula, Aero design, Spaghetti bridge, Young SA, among others, is being successful . This has involved many companies or entities as SAE, SEM, BSSM, Petrobrás, Alcoa and others.

We try to emphasize the modern concept of interaction between Solids Mechanics and other Mechanical Engineering subjects. Through Physics, Mechanics, Strength of Materials, Experimental Stress Analysis, Finite Element Method, Computer Aided Project and other disciplines and practical activities, the student starts to become a professional with a broad view of the Mechanical Engineering.

This paper enforces the use of laboratories. In the case of Strength of Materials, we recommend the construction of a didactical laboratory, with simple models, to introduce the student in the subject. Later, it is important to develop an Experimental Stress Analysis Laboratory, with well prepared equipments and experiences, where the future engineer can develop a critical view.

\section{Acknowledgements}

The authors are grateful for the collaboration of Professors R. Bortolussi, M. Lucato, A. Bernardini, S. Delijaicov, G. Donato, R. Montefusco, K. Amann and others, who have contributed, directly or indirectly, to the conclusion of this work. Our special acknowledgement to the CLM, the Mechanical Engineering Department, the Rectory and the Presidency of FEI and to the Board of Directors of EEM/CEUN-IMT. 


\section{References}

[1] R. J. P. C. Miranda, et al. Experimental Stress Analysis and the Mechanical Engineers Courses (2003 SEM Annual Conference and Exposition on Experimental and Applied Mechanics, North Carolina, USA, 2003)

[2] R. J. P. C. Miranda, C. A. M. Santos, Equipamento de Ensaio de Flexão - Uma contribuição para o ensino e aprendizado experimental de Resistência dos Materiais (COBEM-CIDIM, Minas Gerais, Brazil, 1995)

[3] R. J. P. C. Miranda, O uso do Laboratório e Computador no processo de ensino e aprendizado de Resistência dos Materiais (XXIII - COBENGE, Pernambuco, Brazil, 1995)

[4] R. J. P. C. Miranda, et al. Resistência dos Materiais Edited by author, São Bernardo do Campo, SP, Brazil (2002)

[5] G. H. B. Donato, R. F. V. Bôas, Desenvolvimento de Experimentos e Modelos Físicos Quali e Quantitativos para Ilustração de Conceitos de Estática, Resistência dos Materiais e Mecânica dos Sólidos durante Aulas Teóricas e Práticas de Graduação do Centro Universitário da FEI, São Bernardo do Campo, SP, Brazil, (2010)

[6] F. P. Beer, E. R. Johnston, J. T. DeWolf, D. F. Mazurek, Mechanics of Materials 5. Ed. New York: McGraw-Hill, (2009).

[7] R. J. P. C. Miranda, S. Delijaicov, Laboratório de Mecânica dos Sólidos, Edited by author, São Bernardo do Campo, SP, Brazil, (2006)

[8] R. Bortolussi, A. C. Prado, BAJAFEI, Um projeto vitorioso, Revista Pesquisa \& Tecnologia FEI, (2004), p. 2

[9] Modern Stress and Strain Analysis: A state of the art guide to measurement techniques, BSSM, Published by Eureka magazine, (2009)

[10] J. A. Santos, Sobre a Concepção, o Projeto, a Execução e a Utilização de Modelos Físicos Qualitativos na Engenharia de Estruturas, Escola Politécnica da USP, São Paulo, SP, Brazil (1983).

[11] Information on http://www.usdidactic.com

[12] Information on http://www.tecquipment.com

[13] Information on http://www.heliodon.com.br

[14] Information on http://www.maua.br

[15] Information on http://www.fei.edu.br

[16] R. C. Hibbeler, Resistência dos Materiais, 5 ed., São Paulo, SP: PEARSON PRENDICE HALL, (2004).

[17] Information on http://www.bssm.org

[18] Dally, J. W., Riley, W. F.; Experimental Stress Analysis, 3 ed., New York: McGraw-Hill, (1991).

[19] J. M. Avril, Encyclopédie D'Analyse des Constraintes, Ed. Vishay Micromessures, (1984).

[20] M. F. Giorgetti, et al.; O concurso de Projetos e Protótipos como atividade educacional e seleção para o mercado de trabalho, Edited by ABENGE, vol. 28, N. 01, (January - July 2009)

[21] Information on http://www.hbm.com

[22] Information on http://www.vishay.com

[23] Information on http://www.excelsensor.com.br

[24] Information on http://www.kyowa-ei.co.jp

[25] Information on http:/www.sem.org 